OPEN ACCESS

\title{
The time to act is now: pseudo-systematic review
}

\author{
Nathan Ford, ${ }^{1}$ Grania Brigden, ${ }^{2}$ Tom Ellman, ${ }^{3}$ Edward J Mills ${ }^{4}$
}

Check for updates

${ }^{1}$ Centre for Infectious Disease Epidemiology and Research,

School of Public Health,

University of Cape Town

Observatory 7925, South Africa

${ }^{2}$ Department of Tuberculosis,

International Union Against

Tuberculosis and Lung Disease, Geneva, Switzerland

${ }^{3}$ South African Medical Unit, Médecins Sans Frontières, Cape

Town, South Africa

${ }^{4}$ Department of Health Research Methods, Evidence, and Impact, McMaster University, Hamilton, Canada

Correspondence to: N Ford Nathanpford@gmail.com

(ORCID 0000-0003-1482-3967) Additional material is published online only. To view please visit the journal online.

Cite this as: $B M J$ 2020;371:m4143 http://dx.doi.org/10.1136/bmi.m4143

Accepted: 7 October 2020

\section{ABSTRACT \\ OBJECTIVE}

To identify any medical or public health rationale for claims that the time to act is now.

\section{DESIGN}

Pseudo-systematic review.

\section{DATA SOURCES}

PubMed.

\section{STUDY SELECTION}

Studies that included the claim "time is now" in the title, with or without exclamation marks. No language or date restriction was applied.

\section{RESULTS}

512 articles were included for review. No relationship was identified between time to act and disease burden, severity, or specialty. Claims that the time to act was Christmas were almost entirely without basis. A clustering of claims that it is time to act in the first quarter of the year suggested a possible association with New Year's resolutions.

CONCLUSIONS

Now is as good a time as any.

\section{Introduction}

"There is almost no such thing as ready. There is only now. And you may as well do it now. Generally speaking, now is as good a time as any"

\section{Hugh Laurie (AKA Dr House)}

The time to act is now! This is a commonly used clarion call in medical journals. It can be found in titles of editorials, commentaries, letters, and, occasionally, original research. During 2020 health systems around the world were stretched to breaking point managing the coronavirus disease 2019 (covid-19) pandemic. Nevertheless, we were told that the time is now to standardise sedation training, ${ }^{1}$ differentiate service delivery, ${ }^{2}$ certify cardiac anaesthetists, ${ }^{3}$ address the mental health impact of climate change, ${ }^{4}$ and end the HIV epidemic. ${ }^{5}$

Two articles claimed that the time is now to consider universal mask wearing to protect against covid-19 which, to be fair, was timeous. ${ }^{6}$ Nevertheless, we are concerned about the potentially endless stream of demands placed on health professionals around the world to Act Now! without any obvious rationale, and little regard for competing priorities. Claims that

\section{WHAT IS ALREADY KNOWN ON THIS TOPIC}

Articles across specialties increasingly implore us that it is time to act

\section{WHAT THIS STUDY ADDS}

The findings of this review suggest that someone, somewhere, thinks that the

time to act is now the time is now have doubled in the past decade, from 26 articles published in 2010 to 52 in 2019 (fig 1). We suspect 2020 will be a bumper year.

One of us had the idea years ago to undertake a review of papers that claimed the time for action is now. However, there never seemed to be a good time. Each time a new study got published claiming the time for something or other is now, there would be a brief increase in motivation, but this would soon fade. Finally, in May 2020, with nowhere to go and little to do at weekends, we decided it was time to act.

\section{Methods}

We searched up to 30 September 2020 for studies that made the claim "time is now" in the title. We intended to search the grey literature via Google Scholar but after an initial screen yielded 6.6 million results we decided to omit this step. We used the General Medical Council list of specialties ${ }^{8}$ to explore whether levels of impatience differed by specialty. No date or language restriction was applied.

It has been suggested that Christmas time is the season to be lazy. ${ }^{9}$ We explored which disciplines considered the time to act was Christmas by tabulating articles published on the nearest day to Christmas from 2010 to 2019 (see table 1) and assessed the appropriateness of these claims through visual inspection of results and applying personal opinion.

We were unsure whether authors only wanted people to act now, or whether deferred action was also a desirable goal. We therefore undertook a sensitivity analysis that included the following statements: "the time to act is later" and "the time to act is in a bit." We carried out subgroup analyses to assess the use of question marks or exclamation marks to provide particular emphasis to the claim that time is of the essence.

\section{Patient and public involvement}

No patients or members of the public were involved in the conduct of this review-we assume that the public is not consulted before the authors telling them to act now.

\section{Results: is now the time?}

Our initial search yielded 595 titles, of which 512 studies were included for review. On screening of the abstracts we noted that only 16 articles (3\%) could be considered related to research, suggesting that claims that the time is now are rarely empirically derived. Of 46 articles claiming the time is now during 2020, only three called for action against the ongoing pandemicone about serosurveys ${ }^{10}$ and two about masks. ${ }^{6} 7$ The rest either made reference to the pandemic opportunistically to promote a perennial concern, or didn't refer to it at all. 


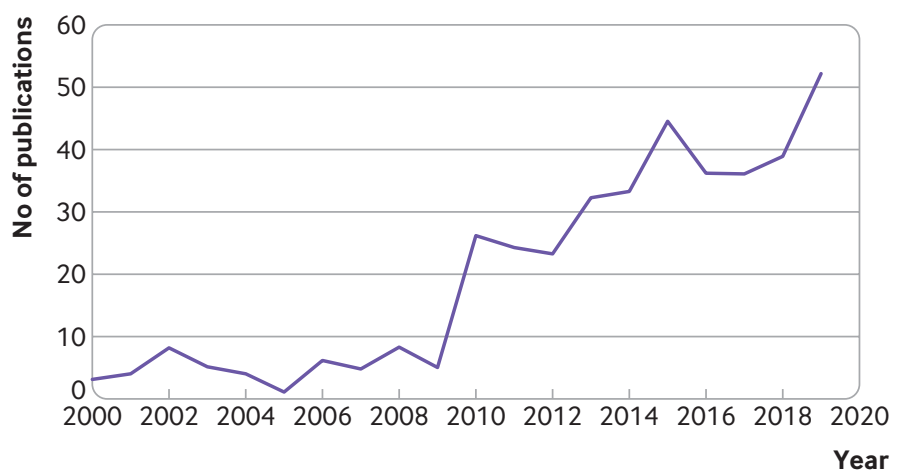

Fig 1 | Time is increasingly Now. Claims made in the past 20 years. Data from PubMed

We excluded 77 studies that used a question mark in the title. Authors asked questions such as: Is now the time for combination therapies for Alzheimer's disease? Is now the time to abolish breast cancer screening in Hong Kong? Is now the time to set standards for quality of care for irritable bowel syndrome? Is now the time to abolish asbestos? ${ }^{11-14}$ We are unable to determine with certainty whether the question mark was added to truly express uncertainty. We were, however, aware of the rhetorical "straw man" fallacy, which Wikipedia defines as "giving the impression of refuting an opponent's argument, while actually refuting an argument that was not presented by that opponent." We therefore took a convenience sample of 10 of these studies to determine whether genuine uncertainty exists about whether now was the time to act. Study selection was based on being able to access the full text free of charge and without having to bother logging into multiple journal sites using a friend's library access. We estimated that most of them (7/10) were straw man arguments (data not shown because claim was based more on a feeling).

We excluded one study that asked: Paediatric AIDSis now not the right time to act? ${ }^{15}$ because another group of clinicians had beaten them to it by asking exactly the same question the year before, in the same journal $^{16}$ (the answer, both times, was yes).

We included studies that used exclamation marks, even though most style guides agree that they should never be used. ${ }^{17}$ We found 50 studies that used an exclamation mark, presumably because stating that the time to act is now was considered insufficient to express urgency. Examples include: Colorectal cancer screening (The time is now!), ${ }^{8}$ Collaboration between nurses and doctors (The Time is Now!), ${ }^{18}$ and Next-generation molecular genetic diagnostics in nephrology (the time is now!). ${ }^{19}$ Thankfully, no studies were identified that used multiple exclamation marks.

\section{The time to act is Christmas}

We undertook a subgroup analysis to determine the Yuletide relevance of eligible studies published at Christmas over the past decade (table 1 ). Of these, only one paper-Alcohol and the elderly: the time to act is now!-could be considered to have some relevance to Christmas. The rest could have been published at any time of year.

In 2019, 49 published articles instructed that it was time to act, with a clustering of articles in the first three months of the year (19 articles, versus 10 articles for other quarters). While differences are not statistically significant, this upsurge in the first quarter of the year could be associated with New Year's resolutions.

\section{Differences by specialty: impatience or laziness?}

Claims about urgency varied by discipline. The greatest number of papers claiming the time is now were found for oncology (72 studies), surgery (60 studies), and paediatrics (33 studies). Paediatricians were almost five times more likely than geriatricians (seven studies) to claim that the time to act is now, possibly reflecting how critical the passage of time is for children. ${ }^{30}$ We were unable to find any studies published by dermatologists or ophthalmologists, suggesting that either they were too busy or they did not have pressing issues that need to be acted upon now. There was substantial unexplained within-specialty heterogeneity. Within infectious diseases, 11 studies claimed that the time to act against HIV was now, compared with two for tuberculosis, and none for malaria; this suggests making claims about the time to act has little to do with disease burden or mortality. To corroborate this hypothesis, we found no studies claiming that the time to act against Ebola virus disease is now, despite the disease having a $50 \%$ case fatality rate. Possibly, those working on the disease were too busy acting to write about the need to act.

\begin{tabular}{|c|c|c|}
\hline $\begin{array}{l}\text { Date of } \\
\text { publication }\end{array}$ & $\begin{array}{l}\text { When is it } \\
\text { time to act? }\end{array}$ & Issue requiring Yuletide action \\
\hline December 2019 & Now & The opioid epidemic and psychiatry: the time for action is now ${ }^{20}$ \\
\hline December 2018 & Now & Paid parental leave in radiology: the time is now ${ }^{21}$ \\
\hline December 2017 & Now & Reducing radiation exposure from nuclear myocardial perfusion imaging: time to act is now ${ }^{22}$ \\
\hline December 2016 & Now & Time is now: venous thromboembolism prophylaxis in blunt splenic injury ${ }^{23}$ \\
\hline December 2015 & Now & Making physical activity counselling a priority in clinical practice: the time for action is now ${ }^{24}$ \\
\hline December 2014 & Now & Understanding the risk of donor-derived infections in paediatric transplantation: the time is now ${ }^{25}$ \\
\hline December 2013 & Now & The time is now to fix SGR ${ }^{26}$ \\
\hline December 2012 & Now! & $\begin{array}{l}\text { Interprofessional Education (IPE) Activity among health sciences students at Sultan Qaboos University: } \\
\text { the time is now! }\end{array}$ \\
\hline December 2011 & Now & End-of-life care: the time for a meaningful discussion is now ${ }^{28}$ \\
\hline December 2010 & Now! & Alcohol and the elderly: the time to act is now! $!^{29}$ \\
\hline
\end{tabular}




\section{Let's wait a bit}

We were unable to find any studies that claimed "the time to act is later" or "the time to act is after a nap," or "let's wait a bit." One study used the words "to do it now or later" in the title, but this discussed the neural correlates of procrastinations and was possibly the only study to ever have meaningfully used the time is now construct. ${ }^{31}$

Although we were unable to identify any articles that explicitly stated the time to act was later on, we realise that many journals have lengthy publication processes. These delays would need to be factored in such that authors who felt the time to act was Christmas would need to submit their paper in July. As we did.

\section{Whose time is it to act?}

We reviewed 10 articles published since 2017 to determine the level of specificity attached to the imperative to act swiftly. None of these articles specified who was supposed to act, or what they were supposed to do. This risks promoting Diffusion of Responsibility, whereby the probability of anyone acting is diminished as the number of potential actors increases. If everyone is told to act, each individual is more likely to act as a Bystander, to Morally Disengage and-our personal favourite-to Socially Loaf. ${ }^{32}$

\section{Discussion}

The findings of our review suggest that it is always time to act. An important limitation of our review is that we did not assess whether appeals to act now changed behaviour, including the behaviour of the authors making the claim. Editorials, while potentially powerful motivating materials, are hardly matched by basic efforts to actually conduct the advocated approach.

The claim that the time is now! is rarely found in corrections, for example when authors have had second thoughts about when to act. It is also never found in obituaries. No link is seen between whether the topic in question really does deserve action today, as opposed to yesterday or tomorrow. Our study was limited to claims made in the title. We suspect that if we broadened our search to include, for example, the last line of study conclusions, many more examples would have been found. We doubt however, that any of them would have a stronger basis for their claim.

If it is always time to act, this led us to wonder why the complacency? A rapid search found 40 articles with the words "No room for complacency" in the title. This could be an interesting question for future $B M J$ Christmas research.

Contributors: This review was conceived by NF. One of the other authors (GB) engaged in this project as soon as they heard about it, suggesting positive bias towards acting now. The other authors have been mulling this over for about a decade without getting around to it, and so can be assumed to have no conflict. NF acts as guarantor, and attests that all listed authors meet authorship criteria and that no others meeting the criteria have been omitted.

Funding: None.

Competing interests: All authors have completed the ICMJE uniform disclosure form at www.icmje.org/coi disclosure.pdf and declare: no support from any organisation for the submitted work; no financial relationships with any organisations that might have an interest in the submitted work in the previous three years; no other relationships or activities that could appear to have influenced the submitted work. Ethical approval: Not required.

Data sharing: No additional data available.

The lead author (the manuscript's guarantor) affirms that the manuscript is an honest, accurate, and transparent account of the study being reported; that no important aspects of the study have been omitted; and that any discrepancies from the study as planned have been explained.

Dissemination to participants and related patient and public communities: This research is intended as a refrain to authors writing titles of medical manuscripts. As such, publication in the $B M J$ appears to be an ideal way to disseminate our findings.

Provenance and peer review: Not commissioned; externally peer reviewed

This is an Open Access article distributed in accordance with the Creative Commons Attribution Non Commercial (CC BY-NC 4.0) license, which permits others to distribute, remix, adapt, build upon this work non-commercially, and license their derivative works on different terms, provided the original work is properly cited and the use is noncommercial. See: http://creativecommons.org/licenses/by-nc/4.0/.

1 Toney M, Pattishal S, Garber M. The time is now: Standardized sedation training for pediatric hospitalists. Pediatrics 2020;145:e20200446. PubMed doi:10.1542/peds.2020-0446

Wilkinson L, Grimsrud A. The time is now: expedited HIV differentiated service delivery during the COVID-19 pandemic. I Int AIDS Soc 2020;23:e25503. PubMed doi:10.1002/jia2.25503

3 Troianos CA. The time is now for board certification in cardiac anesthesia. / Cardiothorac Vasc Anesth 2020;34:573-4. PubMed doi:10.1053/j.jvca.2019.11.031

4 Seritan AL, Seritan I. The time is now: climate change and mental health. Acad Psychiatry 2020;44:373-4. PubMed doi:10.1007/ s40596-020-01212-1

5 Giroir BP. The time is now to end the HIV epidemic. Am J Public Health 2020;110:22-4. PubMed doi:10.2105/AJPH.2019.305380

6 Gandhi M, Havlir D. The time for universal masking of the public for coronavirus disease 2019 is now. Open Forum Infect Dis 2020;7:ofaa131.

7 Brooks JT, Butler JC, Redfield RR. Universal masking to prevent SARSCoV-2 transmission-the time is now. JAMA 2020;423:635-7. PubMed doi:10.1001/jama.2020.13107

8 General Medical Council. GMC approved postgraduate curricula. 2020. https://www.gmc-uk.org/education/standards-guidance-andcurricula/curricula

9 Collington R. Tis the season to be lazy: 10 things you say you're going do this Christmas but never will. Independent. 2013. https:// www.independent.co.uk/student/student-life/tis-season-be-lazy-10 things-you-say-you-re-going-do-christmas-never-will-9009972 html

10 Peeling RW, Olliaro PL. The time to do serosurveys for COVID-19 is now. Lancet Respir Med 2020;8:836-8. PubMed doi:10.1016/ S2213-2600(20)30313-1

11 Morris JC. Editorial: is now the time for combination therapies for Alzheimer Disease? J Prev Alzheimers Dis 2019;6:153-4. PubMed

12 Chow LC. Is now the right time to abolish breast cancer screening in Hong Kong? Hong Kong Med / 2018;24:216-7. PubMed doi:10.12809/hkmj185079

13 Lacy BE, Ford AC, Talley NJ. Quality of care and the irritable bowel syndrome: is now the time to set standards? Am J Gastroenterol 2018:113:167-9. PubMed doi:10.1038/ajg.2017.442

14. A ban on asbestos: is now the time? CMAJ 2001;164:453-5, 455. PubMed

15 Mclntyre J, Gray G, Johnson S. Paediatric AIDS--is now not the right time to act? S Afr Med I 1998;88:466-7. PubMed

16 Matchaba PT, Chapanduka ZC. Paediatric AIDS--is now not the right time to act? S Afr Med / 1997;87:1343-5. PubMed

17 Forsythe M. Beware!!! The President absolutely loves exclamation marks. Spectator 2018. https://www.spectator.co.uk/article/beware-

18 Tumulty G, Nurse-physician collaboration. Nurse-physician collaboration: the time is now! Aspens Advis Nurse Exec 1993;8:1-2, 8. PubMed

19 Harris PC. The time for next-generation molecular genetic diagnostics in nephrology is now! Kidney Int 2018;94:237-9. PubMed doi:10.1016/j.kint.2018.03.025

20 Brunette MF, Oslin DW, Dixon LB, et al. The opioid epidemic and psychiatry: the time for action is now. Psychiatr Serv 2019;70:116871. PubMed doi:10.1176/appi.ps.201800582

21 Arleo EK. Paid parental leave in radiology: the time is now-challenges, strategies, and the business case for implementation. J Am Coll Radiol 2019:16:389-92. PubMed doi:10.1016/j.jacr.2018.10.031 
22 Gupta A, Bajaj NS. Reducing radiation exposure from nuclear myocardial perfusion imaging: Time to act is now. J Nucl Cardio 2017;24:1856-9. PubMed doi:10.1007/s12350-017-0915-y

23 Kwok AM, Davis JW, Dirks RC, Wolfe MM, Kaups KL. Time is now: venous thromboembolism prophylaxis in blunt splenic injury. Am / Surg 2016;212:1231-6. PubMed doi:10.1016/j. amjsurg.2016.09.026

24 Berra K, Rippe J, Manson JE. Making physical activity counseling a priority in clinical practice: the time for action is now. JAMA 2015;314:2617-8. PubMed doi:10.1001/jama.2015.16244

25 Green M, Covington S, Blumberg EA. Understanding the risk of donor-derived infections in pediatric transplantation: the time is now. Pediatr Transplant 2015;19:8-10. PubMed doi:10.1111/petr.12380

26 Leavitt M, Shalala D, Foster R. The time is now to fix SGR. Mod Healthc 2013;43:21. PubMed
27 Inuwa IM. Interprofessional Education (IPE) Activity amongst health sciences students at Sultan Qaboos University: the time is now! Sultan Qaboos Univ Med / 2012;12:435-41. PubMed doi:10.12816/0003168

28 Petasnick WD. End-of-life care: the time for a meaningful discussion is now. J Healthc Manag 2011;56:369-72. PubMed doi:10.1097/00115514-201111000-00004

29 Scafato E. Alcohol and the elderly: the time to act is now! Eur J Public Health 2010;20:617-8. PubMed doi:10.1093/eurpub/ckq112

30 Save the Children. USA. His name is Today, by Gabriel Mistral. 2020 https://www.youtube.com/watch?v=A-H-f2ldKlw.

31 Zhang S, Liu P, Feng T. To do it now or later: The cognitive mechanisms and neural substrates underlying procrastination. Wiley Interdiscip Rev Cogn Sci 2019;10:e1492. PubMed doi:10.1002/wcs.1492

32 Karau S, Williams K. Social loafing: research findings, implications, and future directions. Curr Dir Psychol Sci 1993;65:681-706. 